\title{
The main directions in the implementation of organic agriculture
}

\author{
N.P. Zuev*, N.N. Shvetsov, Y.P. Breslavets, V.A. Shumsky, and Y.P. Masalykina \\ Belgorod State Agrarian University named after V. Y. Gorin, Belgorod, Russia
}

\begin{abstract}
Measures for the introduction of organic agriculture, along with the use of appropriate techniques in agriculture, imply the rejection of the use of chemical-synthetic growth regulators or hormones; limited, strictly tied to the area, livestock; feeding animals, if possible, with their own feed, minimum purchase of feed and avoiding antibiotics. However, there is currently no way to permanently stop using antibiotics. Therefore, a gradual decrease in doses, frequency and timing of their application is relevant. The work is devoted to the implementation of this direction. A synergistic relationship of gentamicin and tylosin was established with an increase in the efficiency of using the created composite preparation with a decrease in the dose and the possibility of the formation of drug-resistant populations of bacteria - causative agents of animal diseases.
\end{abstract}

\section{Introduction}

The main idea of organic farming is to manage the farming in accordance with the laws of nature. At the same time, an agricultural enterprise is considered, first of all, as an organism with its constituent parts - man, animal, plant and earth. It is planned to increase the consumption of organic products in the Belgorod region. At the same time, the speed of this process is not sufficient and does not correspond to the needs of society. In 2020, this economic and social direction accounted for $1-3 \%$ of the total volume of livestock production of all types of property.

Purpose: development and implementation of the main elements of organic agriculture in animal husbandry in the system of organic-rational relationship of its constituent parts: land, plants, animals and humans.

The main directions of the implementation of organic agriculture include: rejection of plant protection products with chemical-synthetic means; the use of slow-acting natural fertilizers (encapsulated and nanostructured pesticides of various directions); refusal to use chemical-synthetic growth regulators or hormones; livestock associated with land; production of animal feed directly on the farm; development of antibiotic substitution measures and minimization of their harmful effect on the earth-plant-animal-human system (the main components of organic agriculture).

\footnotetext{
*Corresponding author: zuev_1960_nikolai@mail.ru
} 


\section{Materials and methods}

An important component of the relationship in the earth-plant-animal-human system is the production of micronutrient-enriched food products: the production of fortified human food products up to $25-35 \%$ (by 2030); the fortification of dairy products, flour and bread with minerals and vitamins [6] An important social moment is the possibility of consumption of food products enriched with micronutrients by adults with low and low incomes and children in social institutions, as well as their use in the prevention of pathologies associated with a lack of biologically active substances in humans (vitamins, vitamin-like substances, macro- and microelements).

Organizational and economic support for the implementation of organic agriculture necessarily provides for the associated and coordinated activities in agricultural technology, fodder production, plant and animal protection, processing industry technologies at the regional, municipal level of action [6].

In the presence of livestock on the farm, the necessary need for feed (coarse, juicy, green, concentrated) is determined, and how much feed will be obtained from natural lands. The missing amount of forage must be produced on arable land [6].

Determine which crops will cover the need for hay, silage, haylage, green fodder and concentrates.

In relation to organic livestock are needed [6]:

- description of premises in which animals are raised, areas for outdoor walking, pastures, outdoor trails, etc., as well as premises for slaughter of animals and premises for packaging and storage of animal products, incoming materials and raw materials;

- a complete description of the manure warehouses or storage areas that are obtained from the breeding of animals;

- contracts concluded with other producers (if necessary), when applying manure, which was obtained during the breeding of animals;

- information on breeding or origin of livestock;

- information about the purchase or sale of livestock;

- a veterinary care plan used to prevent and treat disease, injury and reproductive problems;

- information on all medical procedures and medicines used for any purpose, including for the purposes of ensuring the quarantine period and processing of animals;

- information about purchased feed and its sources, animal rations;

- information on the movement of livestock within the production unit;

- information on the transportation, slaughter and sale of animals outside the production unit.

As an example, the specific implementation of one of the areas of organic farming, and organic agriculture in general, we present the technology for the development of the production and use of composite antimicrobial drugs, which determine their use in lower doses and thereby reduce their intake into the body of animals during their treatment and prevention of diseases, people with food, together with manure into the soil, reducing the possibility of the formation of drug-resistant populations of bacteria - causative agents of diseases of animals and humans and their harmful effect on the biological components of the soil. The use of such funds helps to increase the rate of elimination (excretion) of them from the body of animals.

\section{Results and discussion}

\section{Example No. 1}

The drug for therapy with Escherichiosis gastroenteritis of piglets 
The proposed invention relates to animal husbandry and can be used for therapy with Escherichiosis gastroenteritis of piglets.

Known drugs for therapy with gastroenteritis of pigs using various antibacterial agents: tanibel, phosphopag, combinations of tylosin, nitrofurans, and nitazole [7, 8, 9, 12]. Therapeutic efficacy in gastroenteritis of piglets has fradizin itylosin tartrate $[1,2,3$, 4]. Tylosin tartrate is one of the preparations for microbiological synthesis. The disadvantages of tylosin-containing preparations and other above-mentioned preparations, including in relation to $\mathrm{E}$. coli, are: a narrow spectrum of activity in relation to microorganisms that cause gastroenteritis in pigs, the rapid emergence of pathogens of resistance to them. Based on the foregoing, the task of the invention is set: the creation of a drug for therapy for Escherichiosis gastroenteritis of pigs by increasing the prophylactic activity of tylosin for gastroenteritis of pigs by increasing its antimicrobial activity and the creation of its composite forms.

When solving the task, it was necessary:

1. Expansion of the range of antimicrobial drugs in severe infections against microbial pathogens of gastroenteritis in piglets that require immediate initiation of treatment before bacteriological diagnosis, or in mixed infection, when pathogens of microbial association have different susceptibility to antibacterial drugs.

2. To prevent the development of toxic effects by achieving a rapid and more complete effect with the simultaneous introduction of two or more drugs in smaller than usual, course doses. This is important when using antibiotics that cause nephrotoxic (aminoglycosides, polymyxin, griseofulvin), hepatotoxic (tetracycline, erythromycin, novobicin) effects, adverse effects on the gastrointestinal tract (tetracycline (chloracycline, erythioramine, erythiram).

3. Achieving a potential antibacterial effect.

4. Reduction or elimination of the possibility of the acquired drug resistance of pathogenic microorganisms.

Based on the above requirements, macrolide, nitrofuran and aminoglycoside (gentamicin) drugs are promising as means for creating composite antibacterial drugs with a wide spectrum of action.

Tylosin-containing drugs have high antimicrobial activity against gram-positive and relatively low - gram-negative microflora. Nitrofuran compounds exhibit a broad range of antimicrobial activity

Previously, we found that a synergistic combination of tylosin tartrate with furazonal in a ratio of 3: 1 is effective in treating sick animals and preventing the development of gastroenteritis in piglets. This combination is effective when administered with feed at a dose of $10 \mathrm{mg} / \mathrm{kg}$ body weight $[5,6,7]$. However, due to the limited use of nitrofuran drugs and the insufficient effectiveness of the above drugs, as well as the need to prevent the formation of bacterial resistance, the use of antibiotics from the aminoglycoside group (gentamicin) is more promising.

We have carried out laboratory studies that determine the optimal ratio of components in the created composite agent while studying their antimicrobial action against bacteria that play an etiological role in the occurrence of gastroenteritis in pigs. The results of the studies are presented in table 1. 
Table 1. Antimicrobial activity of the composition of tylosin tartrate with gentamicin.

\begin{tabular}{|c|c|c|c|c|c|c|c|c|}
\hline \multirow{3}{*}{$\begin{array}{l}\text { Type of micro- } \\
\text { organisms }\end{array}$} & \multicolumn{5}{|c|}{ Minimum bacteriostatic concentration (MBK, $\mu \mathrm{g} / \mathrm{ml}$ ) } & \multicolumn{2}{|c|}{$\begin{array}{l}\text { Fractional inhibitory } \\
\text { concentration }(\mu \mathrm{g} / \\
\mathrm{ml}) \text { in a } 1: 1 \text { ratio }\end{array}$} & \multirow{3}{*}{$\begin{array}{l}\text { FIC- } \\
\text { index of } \\
\text { the } \\
\text { compoun } \\
\text { d }\end{array}$} \\
\hline & \multirow[t]{2}{*}{$\begin{array}{l}\text { tylosin } \\
\text { tartrate }\end{array}$} & \multirow[t]{2}{*}{$\begin{array}{c}\text { gentami } \\
\text { cin }\end{array}$} & \multicolumn{3}{|c|}{$\begin{array}{l}\text { compositions of tylosin tartrate with } \\
\text { gentamicin }\end{array}$} & \multirow[t]{2}{*}{$\begin{array}{l}\text { tylosin } \\
\text { tartrate }\end{array}$} & \multirow[t]{2}{*}{$\begin{array}{l}\text { Gentam } \\
\text { icin }\end{array}$} & \\
\hline & & & $3: 1$ & $2: 1$ & $1: 1$ & & & \\
\hline Escherichia coli & $15 \pm 0,17$ & $10 \pm 0,12$ & $7,03,1 \pm 0,7$ & $6,0 \pm 0,8$ & $5,0 \pm 0,4$ & 0,15 & 0,25 & 0,40 \\
\hline
\end{tabular}

The information presented in Table 1 on the search for the most effective proportions of the constituent ingredients of the composite preparation indicate the potentiation of the antimicrobial activity of the combination of tylosin tartrate with gentamicin in a 1: 1 ratio. The fractional inhibitory concentration (FIC) of tylosin tartrate in relation to E. coli when interacting with gentamicin was 0.15 , and that of gentamicin -0.25 , and the fractional inhibitory index of the composite compound in relation to a microorganism was respectively equal to 0.40 , which predetermined the prospects for further drug development.

Prevention of adaptation in causative agents of gastroenteritis to tylosin tartrate, which occurs after 30 passages, 30 was studied in a separate experiment, the results of which are reflected in table 2 .

Table 2. Prevention of adaptation of microorganisms to causative agents of gastroenteritis in piglets.

\begin{tabular}{|c|c|}
\hline \multicolumn{2}{|c|}{ Bacteriostatic concentration of tylosin tartrate, $\mu \mathrm{g} / \mathrm{ml}$ nutrient medium } \\
\hline $\begin{array}{c}\text { Background (MBK after the } \\
\text { first passage) }\end{array}$ & $\begin{array}{c}\text { After 30 passages on culture media } \\
\text { containing gentamicin }\end{array}$ \\
\hline Colibacillus & Colibacillus \\
\hline $15 \pm 0.14$ & $15 \pm 0.14$ \\
\hline
\end{tabular}

From the data in Table 2, it can be seen that the antimicrobial activity of tylosin tartrate against Escherichia coli did not change even after 30 passages.

In an experiment to study the therapeutic effect of a composite drug at a dosage of 10 $\mathrm{mg} / \mathrm{kg}$ of body weight (animals received the drug with food for 10 days), the results of which are presented in Table 3, its high therapeutic efficacy $(90 \%)$ was established, compared with its components (80\%).

Table 3. Comparative therapeutic efficacy of drugs for gastroenteritis of pigs.

\begin{tabular}{|c|c|c|c|c|}
\hline \multirow{2}{*}{$\begin{array}{c}\text { Group of animals } \\
\text { nnyyn}\end{array}$} & \multirow{2}{*}{$\begin{array}{c}\text { Composite } \\
\text { preparation }\end{array}$} & Tylosin & Gentamicin & \multirow{2}{*}{ Control } \\
\cline { 3 - 5 } & 20 & 20 & 20 & 20 \\
\hline $\begin{array}{c}\text { The number of sick pigs at the } \\
\text { beginning of the experiment } \\
\text { (heads) }\end{array}$ & 18 & 16 & 16 & 15 \\
\hline $\begin{array}{c}\text { Recovered } \\
\text { - piglets (head) }\end{array}$ & 90 & 80 & 80 & 75 \\
\hline
\end{tabular}

The present invention is a compositional preparation for therapy for colorectal gastroenteritis in pigs by administering to piglets a composition of tylosin tartrate and gentamicin in a 1: 1 ratio. The compositional preparation is effective for piglets from 2 
weeks to 4 months of age. The use of a developed and tested composite preparation with feed is the most technologically advanced and economically feasible method.

\section{Example No. 2}

Composite preparation for the treatment of gastroenteritis in dysentery.

The present invention relates to veterinary medicine and can be used for the treatment of piglet gastroenteritis caused by brachispira. Known drugs for the treatment of gastroenteritis of pigs using various antibacterial agents: tetracyclines, oxamycins, macrolides and fluoroquinolones, as well as immunoglobulin-C. It is known that fradizin and other tylosin preparations have therapeutic efficacy in piglet gastroenteritis [1. 2, 3, 4, $5,10,11]$. However, they have a narrowly targeted antibacterial effect [1].

Tylosin is one of the preparations for microbiological synthesis. The disadvantages of tylosin-containing drugs are: a narrow spectrum of activity in relation to microorganisms that cause gastroenteritis in piglets, the rapid emergence of pathogens of resistance to them.

The objective of the invention: increasing the therapeutic activity of tylosin in dysentery gastroenteritis of pigs. Based on the above requirements, the macrolide preparations tylosin and erythromycin are promising for the creation of complex antibacterial agents with a wide spectrum of action. Tylosin-containing drugs have high antimicrobial activity against gram-positive and relatively low - against gram-negative microflora. Erythromycin exhibits a wide range of antimicrobial activity $[1,2,3,4,5]$. A synergistic combination of tylosin tartrate with erythromycin in a 1: 1 ratio is effective in treating sick animals. This combination is effective when administered with feed at a dose of $10 \mathrm{mg} / \mathrm{kg}$ body weight.

Laboratory studies were carried out to determine the optimal ratios of the components in the created composite agent while studying their antimicrobial action against bacteria that play an etiological role in the occurrence of gastroenteritis in pigs. The studies carried out to find the most effective proportions of the constituent ingredients of the composite preparation indicate the potentiation of the antimicrobial activity of the combination of tylosin tartrate with erythromycin in a 1: 1 ratio. The fractional inhibitory concentration (FIC) of tylosin tartrate in relation to Brachispira hyodysenteriae when interacting with erythromycin was 0.4 , for erythromycin, respectively, $0.1 \mu \mathrm{g} / \mathrm{ml}$. FIC - the index of the composite compound for the above microorganisms, respectively, equal to $0.2 ; 0.3 ; 0.3$.

In an experiment to study the therapeutic efficacy of a composite preparation at a dosage of $5 \mathrm{mg} / \mathrm{kg}$ of body weight (animals received the preparation with food for 10 days), its high therapeutic efficacy $(90 \%)$ was established in comparison with its components $(80 \%)$ and in control $-45 \%$.

The data obtained indicate that the therapeutic efficacy of the composite preparation increases due to the synergistic interaction of tylosin tartrate and erythromycin.

The present invention is a composite preparation for the prevention and treatment of piglet dysentery by administering to animals a composition of tylosin tartrate and erythromycin in a 1: 1 ratio. The compositional preparation is effective for piglets from 2 weeks to 4 months of age. The drug is effective at a dose of $5 \mathrm{mg} / \mathrm{kg}$ of body weight of piglets for 10 days in the treatment of dysentery. The introduction of the composite preparation can be started when the first signs of gastroenteritis appear in piglets. The use of a developed and tested composite preparation with feed is the most technologically advanced and economically feasible method.

\section{Conclusions}

Thus, the development of composite prophylactic and therapeutic agents realizes the possibility of reducing the doses of individual pharmacological pharmacological agents and thereby reduces the drug load on the main components of organic farming and agriculture: soil - plants - feed - animals - humans. 


\section{References}

1. V.A. Antipov, B.C. Grishkevich, Technical preparations of antibiotics - effective therapeutic and prophylactic means for veterinary medicine and animal husbandry, Collection of scientific works Pharmacology and toxicology of new drugs and feed additives in veterinary medicine, 171-173 (L., 1990)

2. V.D. Bukhanov, Therapy and prevention of pig dysentery, 24 (Author. Dis ... Cand. vet. n. M., 1986)

3. N.P. Zuev, V.D. Bukhanov, Preparation and development of antimicrobial compositions based on tylosin-containing preparations, Materials of the first congress of veterinary pharmacologists of Russia, 311-316 (Voronezh, RAAS, VNIVIPF and T. - S., 2007)

4. N.P. Zuev, V.D. Bukhanov, Therapeutic efficacy of composite tylosin-containing drugs in acute experience, Materials of the first congress of veterinary pharmacologists of Russia, 307-311 (Voronezh, RAAS, VNIVIPF, 2007)

5. N.P. Zuev, V.A. Shumsky, A.M. Kovalenko, V.Yu. Kovaleva, E.E. Zueva, V.V. Aristov, V.V. Kontsevenko, The use of tylosin preparations in animal husbandry and veterinary medicine, (Monograph Belgorod, 2018)

6. Concept on organic agriculture, (Belgorod, 2013)

7. RU, 2033 172, C1, A61K 35/60 (1995.01), (20.04.1995)

8. RU 2412 702, C1, A61K31 / 351 (2006.01), A61K 31/70 (2006.01), A61 K31 / 341 (2006.01), A61 K31 / 4196 (2006.01), A61 P31 / 09 (2006.01)

9. RU 2337670 C2, A61 K31 / 00 (2006.01), A61 9/48 (2006.01), A61D 7/00 (2006.01)

10. I.Ye. Mozgov, Pharmacology, 416 (M.: Agropromizdat, 1985)

11. A.M. Makukhina, A.G. Rezvykh, O.A. Gavrilova et al., Description of the invention to the copyright certificate (11), 681598 (1981)

12. Z. Sevryuk, Environmental problems of pathology, pharmacology and therapy of animals. - International coordination meeting, 346-348 (Voronezh) 